\title{
Trend of head circumference as a predictor of microcephaly among term infants born at a regional center in Malaysia between 20I I-20I5
}

This article was published in the following Dove Press journal:

Research and Reports in Neonatology

\author{
Rosnah Sutan' \\ May Luu Yeong' \\ Zaleha Abdullah Mahdy ${ }^{2}$ \\ Ahmad Shuhaila ${ }^{2}$ \\ Jaafar Rohana ${ }^{3}$ \\ Shareena Ishak ${ }^{3}$ \\ Khadijah Shamsuddin' \\ Aniza Ismail' \\ Idayu Badillah Idris' \\ Saperi Sulong ${ }^{4}$ \\ 'Department of Community \\ Health, ${ }^{2}$ Department of Obstetrics \\ and Gynecology, ${ }^{3}$ Department of \\ Pediatrics, ${ }^{4}$ Department of Medical \\ Records, Universiti Kebangsaan \\ Malaysia Medical Center, Kuala \\ Lumpur, Malaysia
}

Introduction: The aim of this study was to determine the trend of head circumference as predictor of microcephaly among term infants born in a teaching hospital in Malaysia from 2011 to 2015

Methodology: This was a cross-sectional study using data from the electronic birth census. The independent variables were mothers' age and height, parity, birth weight and birth length. All term newborns, both alive and stillbirth, with 37-41 completed gestational weeks, and a birth weight of at least $500 \mathrm{~g}$ was extracted from the census.

Results: A total of 26,503 newborns fulfilled the inclusion criteria $(13,655$ males, 12,840 females). The mean head circumferences for male and female newborns were $32.93 \mathrm{~cm}$ ( \pm SD $1.32)$ and $32.56 \mathrm{~cm}( \pm \mathrm{SD} 1.31)$. The average head circumference for Malaysian newborns was found to be smaller than the World Health Organization Standard Growth Chart for Term Infant. A total of $17.6 \%(n=4,669)$ of the total samples were observed to have microcephaly. Among them, $73.2 \%(n=3,419)$ were non-proportionate microcephaly with normal birth weight of $2.5 \mathrm{~kg}$ and above. Bivariate analyses showed that all independent variables were significant predictors of microcephaly. Both simple and multiple logistic regressions demonstrated that low birth weight was the most significant predictors for microcephaly (adjusted OR 12.14, 95\% CI 10.80, 13.65). Conclusion: There is an increasing trend of microcephaly across the years and the low birth weight was noted as the main predictor of microcephaly. Future studies are needed to determine the possible cause of increasing microcephaly by controlling for birth weight and gestational age of the neonates. Keywords: SGA, perinatal, growth chart, IUGR, birth parameter, occipito-frontal

\section{Introduction}

Birth parameters are important indicators of prenatal nutritional status and intrauterine environment. In Malaysia, birth weight, length, and head circumference of all infants are measured and recorded in the Child Health Record Book at birth and on clinic visits. These indicators play an important role in monitoring growth and development of the infants. For example, head circumference is used to monitor the growth of brain volume and is known to be a significant predictor of cognitive and intelligence development of a child. ${ }^{1}$ Abnormal head circumference has also been associated with various medical conditions. Microcephaly and macrocephaly are associated with intrauterine infection, toxic environmental exposure, congenital malformation, and various genetic abnormalities. ${ }^{2}$ According to the definition by the Center of Disease Control and Prevention (CDC), microcephaly is diagnosed when occipito-frontal
Correspondence: Rosnah Sutan Department of Community Health, Faculty of Medicine, Universiti Kebangsaan Malaysia Medical Center, Jalan Yaacob Latif, Bandar Tun Razak, 56000 Cheras, Wilayah Persekutuan Kuala Lumpur, Malaysia

Tel +60 I 932I 2256

Email rosnah_sutan@yahoo.com
Research and Reports in Neonatology 2018:8 9-17 
(head) circumference (OFC) falls below the third percentile compared to the appropriately age-matched normal standard; ${ }^{3}$ while macrocephaly is diagnosed when the head circumference measurements are above the $97^{\text {th }}$ percentile.

Although the head circumference at birth is recorded for all newborns in Malaysia, there is no systematic reporting system or analysis on head circumference or microcephaly registry. The existing child health program has been focusing on interventional measures and research on low birth weight and premature infants. With the declaration of the Zika virus as an international public health emergency on February 1, $2015,{ }^{4}$ it is important for Malaysia to establish the baseline information on the incidence and causes of microcephaly, in order to formulate reference values for abnormal head circumference. However, universal screening for all antenatal mothers and babies will incur considerable cost. Therefore, in order to develop a cost-effective microcephaly screening program, the predictive or risk factors associated with microcephaly should be evaluated first prior to planning any such program. A valuable resource of data is a birth center where birth data are recorded.

Zika virus is an arbovirus transmitted by mosquitoes of the Culicidae family and the Aedes genus (sylvatic and urban transmission) including Aedes aegypti (urban transmission). ${ }^{5}$ It is suspected to have a causal link to the spike of increase in babies born with microcephaly and neurological conditions in Brazil in 2015. Zika virus infections have been reported in travelers who visited Thailand ${ }^{6}$ and Malaysia ${ }^{7}$ in recent years. Although there was no report on Zika virus infection among the local population, its vector, $A$. aegypti, is rampant in the Southeast Asian region, transmitting dengue virus and causing widespread dengue fever and dengue hemorrhagic fever in this region.

The last published information on head circumference among Malaysian newborns was in $1994 .{ }^{8}$ Therefore, the head circumference measurement should be repeated to assess the current birth trend. The Ministry of Health Malaysia has adopted the WHO Standard Growth Curve Chart for head circumference since its release in 2006 for better international comparison. ${ }^{9}$ The WHO charts for standard growth describe the growth of healthy children in optimal conditions. ${ }^{9}$ The chart has been incorporated in the child home-based record for child health monitoring. ${ }^{10}$ To date, there are no local studies found in the literature that describe the growth of children in Malaysia using this standard reference. The ability of the WHO standard to represent individual countries and populations has been questioned. ${ }^{11}$ Notably, there was no representative data from the East and Southeast Asian countries, whose population constituted one-fifth of the global population, during the development of the standard charts. Moreover, studies from the East Asian countries have demonstrated a trend of smaller head circumference and birth weight. ${ }^{12,13}$ Similarly, a Malaysian study in 1994 revealed that Malaysian infants were smaller than the standard reference. ${ }^{8}$

The predictors of head circumference of infants have been widely studied. Maternal age, height, pregnancy weight gain, socioeconomic background, lifestyle, and environmental exposure were identified as significant predictors. ${ }^{14-19}$ Advancing maternal age, mothers with short stature, and poor weight gain during pregnancy were identified as contributing factors to smaller infant head circumference. ${ }^{16-18}$ The aims of this study were to establish the trend of head circumference and incidence and predictors of microcephaly among Malaysian term newborns at the Universiti Kebangsaan Malaysia Medical Center (UKMMC) from 2011 to 2015.

\section{Methods}

This is a cross-sectional study, using labor room electronic birth census data from a regional hospital in Malaysia. Total live births recorded in Malaysia for 2015 were 521,136 with $52 \%$ male infants. ${ }^{20}$ The UKMMC represents about $1 \%$ of the total births in Malaysia each year. All birth data in this center were recorded in both manual case records and an electronic data system. Information recorded includes mothers' demographic data and obstetric profile, birth outcome, and newborn profile. Birth outcome was summarized as newborn fit to be discharged to mother, newborn requiring neonatal intensive care unit (NICU) admission, and stillbirth. Details of conditions of newborn such as genetic and chromosomal abnormalities, growth restriction, and physical abnormalities were not recorded in the electronic birth census. Other information such as mothers' medical history, comorbidity, and previous obstetric history were also not recorded in the electronic data system, but were available in the antenatal record books or hospital medical records. Patient consent to review medical records was not required as this was anonymous data retrieved from records with ethics approval.

The data extracted for this study were newborn birth parameters (birth weight, head circumference, and length), and maternal age, height, and parity. Head circumference of newborn was identified as the dependent variable. The study populations were all term live-born and stillborn delivered at UKMMC from January 2011 to December 2015. The measurement taken was based on the assessment of the newborn at birth. No repeat measurement was made 24 hours after birth. The criteria for term infant was birth at $37-41$ completed gestational weeks and birth weight of $\geq 500 \mathrm{~g}$. Cases with incomplete recorded birth parameters were excluded 
from the study. Head circumference was classified into microcephaly, normal head circumference, and macrocephaly for descriptive analysis, and the statistical test for a trend analysis was performed. Microcephaly is defined as having OFC of less than the third percentile compared to appropriate, age-matched, normal standards; ${ }^{3}$ whereas macrocephaly is defined as head circumference above the $97^{\text {th }}$ percentile. Therefore, by using the WHO standard growth curve for head circumference, ${ }^{9}$ which has been implemented in Malaysia in the child home-based card since $2006,{ }^{10}$ the term newborns with head circumference $<32.1 \mathrm{~cm}$ for boys and $<31.7 \mathrm{~cm}$ for girls at birth were categorized as microcephaly, whereas head circumference $>36.9 \mathrm{~cm}$ for boys and $>36.1 \mathrm{~cm}$ for girls at birth were categorized as macrocephaly. Subsequently, newborns with microcephaly and normal head circumference were included for bivariate and multivariate analyses to identify significant predictors. Birth weights were categorized into low birth weights and normal birth weights for analysis. Low birth weight has been defined by WHO as weight at birth of $<2.5 \mathrm{~kg} .{ }^{21}$ Newborn lengths were categorized into short and normal lengths. Newborns with birth lengths of less than the third percentile $(45 \mathrm{~cm})$ according to the WHO Standard Growth Chart ${ }^{9}$ were categorized as having short birth length. ${ }^{10}$

These birth parameters were measured at the time of birth using standardized methods. Newborns were weighed using an electronic weighing scale, and the weights were rounded up to the nearest $0.01 \mathrm{~kg}$. Head circumferences were measured with a plastic measuring tape passing around the widest horizontal OFC, and the lengths were rounded up to the nearest $0.1 \mathrm{~cm}$. Newborn recumbent lengths were measured with knees and legs fully extended, and the lengths were rounded up to the nearest $0.1 \mathrm{~cm}$. Birth parameter measurements were taken only once, by a midwife in the labor room. Repeat measurement is not routinely required, except for newborns with abnormal birth parameters. The latest Perinatal Care Manual ${ }^{22}$ recommended that all newborns with head circumference and birth weight below the tenth percentile to be referred for pediatric assessment. The pediatric medical officer usually repeats the birth parameter measurements for correlation with other clinical findings. As such, we were unable to perform intra- or inter-observer reliability tests in this study as no data were recorded for repeat measures. Nevertheless, all nurses in Malaysia have been trained with the same methods of infant anthropometric measurements by using the Perinatal Care Manual ${ }^{22}$ as the standard protocol. This manual is a comprehensive training manual and the general reference for Malaysian health care providers. Its use has received consensual approval from both the Obstetrician and Pediatrician Committees under the Malaysian Ministry of Health. ${ }^{22}$

Maternal height and weight were recorded in the system using measurements taken at the first visit to UKMMC, either during the antenatal period, or upon arrival for delivery if the mother had never had any antenatal clinic visits at UKMMC. Therefore, pre-pregnancy weight, weight at first antenatal booking, and serial measurements of weight gain during pregnancy according to gestational week were not available in the system, as most mothers had their antenatal bookings done in the Ministry of Health Primary Health Clinics. Data collected on maternal weight in the system consisted of weights from a wide range of gestations, making the data not suitable for analysis. Maternal age, height, and parity upon admission to the labor room were also recorded in the birth census. Maternal height was measured, and the measurement was rounded up to the nearest $0.1 \mathrm{~cm}$. In this study, maternal age, height, and parity were categorized into dichotomous variables based on the risk stratification in the Perinatal Care Manual for analysis. A maternal age $\geq 35$ years was classified as having higher risk of neonatal resuscitation, whereas maternal height $<145 \mathrm{~cm}$, and parity $>5$ were recorded as having higher risk of needing intrapartum intervention. Hospital deliveries are required for mothers with these high-risk profiles.

Statistical analyses were performed using Statistical Package for the Social Science (SPSS), version 21. Initial bivariate analyses were done using chi square tests and simple logistic regression to determine the associations between potential variables and infants' head circumference. Variables with $p$-values $<0.05$ in the chi square tests were selected for multivariate analysis. Multiple logistic regression analysis was used to calculate the odds ratio (OR) of each selected independent variable on the infants' head circumference at birth. The statistical test for a trend in prevalence over time was used.

This study was approved by the Universiti Kebangsaan Malaysia Research Ethics Committee (FF-2016-031) and supported by the University Research Grant (GUP-2014-089).

\section{Results}

A total of 33,292 births were recorded between January 2011 and December 2015. Of the total, 26,503 births (13,655 male and 12,840 female births) that fulfilled the study criteria of term newborn with a birth weight $>500 \mathrm{~g}$ were included for analyses. Nine stillbirths were recorded during the study period. All except eight newborns had complete information on birth parameters. The demographic breakdown of ethnicity among the mothers was $77.8 \%$ Malay, $17.2 \%$ Chinese, $2.5 \%$ 
Indian, and $2.5 \%$ of other races. The mean head circumference was $32.93 \mathrm{~cm}( \pm \mathrm{SD} 1.32)$ for boys and $32.56 \mathrm{~cm}( \pm \mathrm{SD}$ 1.31) for girls.

Table 1 shows the number of term newborns with microcephaly, normal head circumference, and macrocephaly from 2011 to 2015 . The total number of term newborns with microcephaly was 4,669 (17.6\%) within the 5-year period. An increasing trend was observed over the period of time, with the highest number with microcephaly recorded in 2015 , comprising $20.0 \%$ of all term newborns $(n=1,058)$. Among the newborns with microcephaly, 26.8\% $(n=1,250)$ had proportionately small head circumference and birth weight, while $73.2 \%(n=3,419)$ of term newborns had disproportionate microcephaly with a normal birth weight. In terms of birth outcomes of newborns with microcephaly, $91.8 \%$ with proportionate microcephaly and $98.8 \%$ with disproportionate microcephaly were well and allowed discharge to postnatal wards with the mother, after routine assessment by the pediatric medical officer. Table 2 shows the trend analysis of mean head circumference over the years. There is a significant difference noted for mean of head circumference of babies by years of delivery. Table 3 shows a comparison of average head circumference percentiles between our study and a previous study by Boo et $\mathrm{al}^{8}$ in 1994, with reference to the WHO Child Growth Standards for Term Infant. ${ }^{9}$ Generally, Malaysian newborns have smaller head circumference. The head circumference at the third percentile for Malaysian newborns in our study was $30.5 \mathrm{~cm}$ for boys and $30.0 \mathrm{~cm}$ for girls, which were both smaller than the WHO Child Growth
Standards for Term Infant. According to the recommended growth standard, newborns with head circumference $<32 \mathrm{~cm}$ are considered microcephaly, which is equivalent to the $25^{\text {th }}$ percentile of head circumference of all Malaysian newborns in this study (Table 3). Compared to the findings by Boo et al, ${ }^{8}$ the head circumference of male newborns from the $10^{\text {th }}$ to $90^{\text {th }}$ percentile and the head circumference of female newborns from the $50^{\text {th }}$ to $90^{\text {th }}$ percentile were smaller in this study. Table 4 shows the bivariate analysis of the independent variables and head circumference of newborns using chi square test. All independent variables were significant predictors of microcephaly in newborns $(p<0.01)$. Therefore, all independent variables were included in the logistic regression model to assess their OR.

Table 5 shows the results of simple logistic regression and multiple logistic regression analysis of head circumference of newborns and the associated independent variables. All factors were significantly associated with the head circumference of infants $(p<0.01)$ in the simple logistic regression. Birth weight seemed to be the most significant predictor of head circumference of newborns. Newborns with low birth weight were 12 times more likely to have microcephaly than newborns with normal birth weight. This was followed by newborn length, where newborns with a length below the third percentile $(45 \mathrm{~cm})$ were 1.82 times more likely to have microcephaly. Our study also shows that mature mothers aged $>35$ years were $28 \%$ less likely to have newborns with microcephaly than younger mothers. Multiple logistic regressions reaffirmed that birth weight was the most significant

Table I Trend of head circumference among term infants in UKMMC from $201 \mathrm{I}$ to 2015

\begin{tabular}{|c|c|c|c|c|c|c|c|c|c|c|c|c|}
\hline \multirow[t]{2}{*}{ Head circumference } & \multicolumn{2}{|l|}{2011} & \multicolumn{2}{|l|}{2012} & \multicolumn{2}{|l|}{2013} & \multicolumn{2}{|l|}{2014} & \multicolumn{2}{|l|}{2015} & \multicolumn{2}{|l|}{ Total } \\
\hline & $\mathbf{n}$ & $\%$ & $\mathbf{n}$ & $\%$ & n & $\%$ & $\mathbf{n}$ & $\%$ & $\mathbf{n}$ & $\%$ & $n$ & $\%$ \\
\hline Microcephaly & 857 & 15.4 & 778 & 14.7 & 942 & 18.5 & $\mathrm{I}, 034$ & 19.6 & $\mathrm{I}, 058$ & 20.0 & 4,669 & 17.6 \\
\hline Normal HC & 4,617 & 82.8 & 4,389 & 83.2 & 4,053 & 79.7 & 4,182 & 79.1 & 4,161 & 78.8 & 21,402 & 80.8 \\
\hline Macrocephaly & 103 & 1.8 & 108 & 2.0 & 90 & 1.8 & 70 & 1.3 & 61 & 2.0 & 432 & 1.6 \\
\hline Total & 5,577 & 100 & 5,275 & 100 & 5,085 & 100 & 5,286 & 100 & 5,280 & 100 & 26,503 & 100 \\
\hline
\end{tabular}

Abbreviations: UKMMC, Universiti Kebangsaan Malaysia Medical Center; HC, head circumference.

Table 2 Trend analysis of mean head circumference over years

\begin{tabular}{|c|c|c|c|c|c|c|c|c|}
\hline \multirow[t]{2}{*}{ Year } & \multirow[t]{2}{*}{$\mathbf{N}$} & \multirow[t]{2}{*}{ Mean } & \multirow[t]{2}{*}{ SD } & \multirow[t]{2}{*}{ SE } & \multicolumn{2}{|c|}{$95 \%$ Confidence interval } & \multirow[t]{2}{*}{$t$ statistics ${ }^{\mathrm{a}}(d f)$} & \multirow[t]{2}{*}{ p-value } \\
\hline & & & & & Lower bound & Upper bound & & \\
\hline 2011 & 5,474 & 32.858 & 1.3679 & 0.0185 & 32.822 & 32.894 & 39.366 & $<0.001$ \\
\hline 2012 & 5,167 & 32.883 & 1.3145 & 0.0183 & 32.847 & 32.919 & $(426,066)$ & \\
\hline 2013 & 4,995 & 32.671 & I.2846 & 0.0182 & 32.636 & 32.707 & & \\
\hline 2014 & 5,216 & 32.682 & 1.3053 & 0.0181 & 32.647 & 32.718 & & \\
\hline 2015 & 5,219 & 32.640 & 1.3013 & 0.0180 & 32.605 & 32.675 & & \\
\hline Total & 26,071 & 32.748 & 1.3197 & 0.0082 & 32.732 & 32.764 & & \\
\hline
\end{tabular}

Note: 'One way ANOVA.

Abbreviations: ANOVA, analysis of variance; SD, standard deviation; SE, standard error. 
Table 3 Comparison of head circumference percentile between Malaysian term infants and WHO Child Growth Standards for Term Infant

\begin{tabular}{|c|c|c|c|c|c|c|}
\hline \multirow[t]{2}{*}{$\begin{array}{l}\text { Head circumference } \\
\text { percentile }\end{array}$} & \multicolumn{2}{|c|}{$\begin{array}{l}\text { Malaysian term infant } \\
\text { delivered in UKMMC, cm } \\
\end{array}$} & \multicolumn{2}{|c|}{$\begin{array}{l}\text { Malaysian term infant } \\
\left(\text { Boo et } \mathrm{al}^{8}\right), \mathrm{cm}\end{array}$} & \multicolumn{2}{|c|}{$\begin{array}{l}\text { WHO Child Growth Standards } \\
\text { for Term Infant }{ }^{\mathrm{a}}, \mathrm{cm}\end{array}$} \\
\hline & Boys & Girls & Boys & Girls & Boys & Girls \\
\hline $3^{\text {rd }}$ & 30.5 & 30.0 & - & - & 31.9 & 31.5 \\
\hline $5^{\text {th }}$ & 31.0 & 30.5 & - & - & 32.5 & 32.5 \\
\hline $10^{\text {th }}$ & 31.0 & 31.0 & 31.4 & 30.8 & 33.0 & 33.0 \\
\hline $25^{\text {th }}$ & 32.0 & 32.0 & 32.4 & 31.9 & 33.6 & 33.8 \\
\hline $50^{\text {th }}$ & 33.0 & 32.5 & 33.4 & 32.9 & 34.6 & 34.8 \\
\hline $75^{\text {th }}$ & 34.0 & 33.5 & 34.4 & 33.9 & 35.8 & 36.0 \\
\hline $90^{\text {th }}$ & 34.5 & 34.0 & 35.3 & 34.8 & 37.0 & 37.0 \\
\hline $95^{\text {th }}$ & 35.0 & 35.0 & - & - & 37.5 & 37.5 \\
\hline $97^{\text {th }}$ & 35.5 & 35.0 & - & - & 38.0 & 38.2 \\
\hline
\end{tabular}

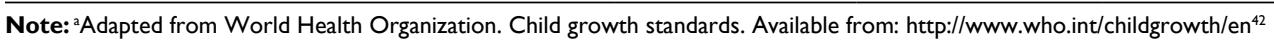

Abbreviation: UKMMC, Universiti Kebangsaan Malaysia Medical Centre.

Table 4 Bivariate analysis of the determinants of $H C$ of infants $(n=26,07 \mathrm{I})$

\begin{tabular}{|c|c|c|c|c|c|c|c|c|}
\hline \multirow[t]{2}{*}{ Variables } & & \multicolumn{2}{|c|}{ Microcephaly } & \multicolumn{2}{|c|}{ Normal HC } & \multirow[t]{2}{*}{$x^{2}$} & \multirow[t]{2}{*}{$d f$} & \multirow[t]{2}{*}{$p$-value } \\
\hline & & $\mathbf{n}$ & $\%$ & $\mathbf{n}$ & $\%$ & & & \\
\hline \multirow[t]{2}{*}{ Maternal age (years) } & $\leq 35$ & 4,087 & 87.5 & 17,878 & 83.5 & 46.23 & 1 & $<0.001$ \\
\hline & $>35$ & 582 & 12.5 & 3,524 & 16.5 & & & \\
\hline \multirow[t]{4}{*}{ Maternal race } & Malay & 3,642 & 78.0 & 16,636 & 77.7 & 17.90 & 3 & $<0.010$ \\
\hline & Chinese & 744 & 15.9 & 3,742 & 17.5 & & & \\
\hline & Indian & 140 & 3.0 & 514 & 2.4 & & & \\
\hline & Other & 140 & 3.1 & 510 & 2.4 & & & \\
\hline \multirow[t]{2}{*}{ Maternal height $(\mathrm{cm})$} & $\leq 145$ & 98 & 2.1 & 192 & 0.9 & 50.33 & 1 & $<0.001$ \\
\hline & $>145$ & 4,571 & 97.9 & 21,210 & 99.1 & & & \\
\hline \multirow[t]{2}{*}{ Parity } & $<5$ & 2,321 & 49.7 & 13,286 & 62.1 & 244.00 & 1 & $<0.001$ \\
\hline & $\geq 5$ & 2,348 & 50.3 & 8,116 & 37.9 & & & \\
\hline \multirow[t]{2}{*}{ Birth weight (kg) } & $<2.5$ & 1,250 & 26.8 & 540 & 2.5 & $3,424.61$ & $\mathrm{I}$ & $<0.001$ \\
\hline & $\geq 2.5$ & 3,419 & 73.2 & 20,862 & 97.5 & & & \\
\hline \multirow[t]{2}{*}{ Birth length $(\mathrm{cm})$} & $<45$ & 377 & 8.1 & 191 & 0.9 & 927.68 & 1 & $<0.001$ \\
\hline & $\geq 45$ & 4,292 & 91.9 & 21,211 & 99.1 & & & \\
\hline
\end{tabular}

Note: $p<0.05$ as significant determinants.

Abbreviation: HC, head circumference;

Table 5 Simple logistic regression and multiple logistic regression of determinants associated with microcephaly $(n=26,07 \mathrm{I})$

\begin{tabular}{|c|c|c|c|c|c|c|c|c|}
\hline \multirow{2}{*}{$\begin{array}{l}\text { Independent } \\
\text { variable }\end{array}$} & & \multicolumn{3}{|l|}{ SLogR $^{a}$} & \multicolumn{4}{|l|}{ MLogR $^{b}$} \\
\hline & & Crude OR & $(95 \% \mathrm{Cl})$ & $p$-value & Adjusted OR & $(95 \% \mathrm{Cl})$ & Wald & $p$-value \\
\hline \multirow[t]{2}{*}{ Mother's age (years) } & $\leq 35$ & 1.00 & & & & & & \\
\hline & $>35$ & 0.72 & $(0.66,079)$ & $<0.01$ & 0.76 & $(0.69,0.84)$ & 28.68 & $<0.01$ \\
\hline \multirow[t]{4}{*}{ Mother's race } & Malay & 1.00 & & & & & & \\
\hline & Chinese $^{c}$ & 0.91 & $(0.83,0.90)$ & 0.03 & 0.87 & $(0.79,0.95)$ & 9.22 & 0.02 \\
\hline & Indianc & 1.24 & $(0.13,0.51)$ & 0.02 & 1.08 & $(0.88,1.34)$ & 0.539 & 0.463 \\
\hline & Other ${ }^{c}$ & 1.28 & $(1.06,1.55)$ & 0.02 & 1.23 & $(1.00,1.51)$ & 3.893 & 0.05 \\
\hline \multirow[t]{2}{*}{ Mother's height $(\mathrm{cm})$} & $\leq 145$ & 2.73 & $(1.85,3.03)$ & $<0.01$ & 2.16 & $(1.64,2.484)$ & 30.15 & $<0.01$ \\
\hline & $>145$ & 1.00 & & & & & & \\
\hline \multirow[t]{2}{*}{ Parity } & $<5$ & 1.00 & & & & & & \\
\hline & $\geq 5$ & 1.66 & $(1.55,1.77)$ & $<0.01$ & 1.59 & $(1.48,1.70)$ & 169.47 & $<0.01$ \\
\hline \multirow[t]{2}{*}{ Birth weight (kg) } & $<2.5$ & 14.13 & $(12.69,15.72)$ & $<0.0$ I & 12.14 & $(10.80,13.65)$ & $\mathrm{I}, 746.47$ & $<0.01$ \\
\hline & $\geq 2.5$ & 1.00 & & & & & & \\
\hline \multirow[t]{2}{*}{ Birth length $(\mathrm{cm})$} & $<45$ & 9.76 & $(8.17,11.65)$ & $<0.01$ & 1.82 & $(1.7,2.27)$ & 29.21 & $<0.01$ \\
\hline & $\geq 45$ & 1.00 & & & & & & \\
\hline
\end{tabular}

Notes: aSimple logistic regression (outcome as head circumference, $\mathrm{cm}$ ). ${ }^{b}$ Multiple logistic regression (Nagelkerke $R^{2}=0.17 \mathrm{I}$ ); the model fits reasonably well; model assumptions are met; there are interactions between parity and mother's age and between parity and birth weight; however no multicollinearity problem was found. 'Wald test for SLogR: Chinese, 4.77; Indian, 5.06; other, 6.60. 
predictor for microcephaly (adjusted OR 12.14), followed by maternal height (adjusted OR 2.16), baby's birth length (adjusted OR 1.82), and multiparity (adjusted OR 1.59). However, Indian and other races were not significant predictors in this logistic model.

Two pairs of independent variables were noted to have interaction, that is, between parity and birth weight, and between parity and maternal age. However, there was no multicollinearity among these independent variables. Hosmer and Lemeshow goodness-of-fit test demonstrated that our data set fitted well with the logistic model. This model was able to predict correctly $84.8 \%$ of infants with microcephaly and explained $17.1 \%$ of variation in the outcome variable.

Table 6 shows the results of simple linear regression and multiple linear regression analyses of head circumference of infants and the associated independent variables. All variables had significant linear relationship with the head circumference of infants $(p<0.01)$. Thus, infants with maternal age of 1 year had larger head circumference by $0.033 \mathrm{~cm}(95 \% \mathrm{CI}$ : $0.030,0.037)$. In a multivariable analysis, it was found that all five independent variables had significant independent effect on newborn head circumference. The models explain $67.7 \%$ of variation in head circumference of newborns in the study sample $\left(R^{2=} 0.677\right)$.

\section{Discussion}

The World Health Organization (WHO) launched new growth standards for infants and children ${ }^{23}$ in 2006 . It was based on the WHO Growth Reference Study on singleton term infants without health, environmental, or economic constraints on growth from India, Brazil, Norway, United States, Ghana, and Oman. However, infants from East and Southeast Asia were not included in the standards development. The WHO assumed that all economically advantaged children who were breastfed as infants grew similarly. ${ }^{9}$ Hence, these standards have been adopted for use internationally to depict how normal children should grow when free from diseases and fed according to recommendations.

The reliability of the standard growth chart for use in this region has been widely studied. ${ }^{11-13}$ Results from these studies showed that our newborns have smaller birth parameters compared to the WHO standard. For example, Japanese breastfed infants are significantly shorter and lighter throughout almost the first 24 months ${ }^{12}$ compared to the WHO growth standard, and infants in Hong Kong are shorter at 36 months. ${ }^{11}$ A Singaporean study demonstrated similar findings. ${ }^{24}$ Among both male and female Singaporean infants at the 38 th gestational week, the $10-50-90^{\text {th }}$ percentile values for head circumference were $1-2 \mathrm{~cm}$ smaller than the WHO growth standard. ${ }^{25}$ Another study on a birth cohort in Jakarta from 2010 to 2011 also found that Indonesian infants were smaller in all three birth parameters than the WHO standard from birth up to 12 months. ${ }^{11}$ The studies in Singapore ${ }^{25}$ and Jakarta, Indonesia, ${ }^{11}$ in the Southeast Asian region concluded that the WHO growth chart does not reflect the current growth of the infant cohort and may have overestimated the birth parameter measurements for gestational age and the diagnosis of microcephaly. As a whole, the results from these studies were similar to our findings on Malaysian infants. Hong Kong and Singapore have adopted their own local reference charts for infant growth monitoring. ${ }^{26,27}$

On the other hand, a Turkish study ${ }^{28}$ reported no disparity in their infant head circumference percentile when compared to Belgian and American infant head circumference percentiles at birth. The United States adopts the WHO standard for child growth from 0 to 24 months, and the subsequent growth is referred to the CDC growth chart for up to 59 months. Deviations from the WHO growth standard should prompt clinicians to identify whether there are suboptimal environmental conditions and to correct the causes of suboptimal growth. Nevertheless, the lack of East Asian and Southeast Asian data in the WHO growth standard could

Table 6 Determinants of head circumference $(\mathrm{cm})$ of infants among the study population for continuous data $(n=26,07 \mathrm{I})$

\begin{tabular}{|c|c|c|c|c|c|c|c|}
\hline \multirow[t]{2}{*}{ Independent variable } & \multicolumn{3}{|l|}{ SLR $^{a}$} & \multicolumn{4}{|l|}{ MLR $^{\mathbf{b}}$} \\
\hline & $\overline{b^{c}}$ & $(95 \% \mathrm{Cl})$ & $\overline{p \text {-value }}$ & Unadjusted $b^{d}$ & $(95 \% \mathrm{Cl})$ & t-stat & $p$-value \\
\hline Maternal age & 0.033 & $(0.030,0.037)$ & $<0.01$ & 0.200 & $(0.017,0.023)$ & 13.901 & $<0.01$ \\
\hline Maternal height $(\mathrm{cm})$ & 0.300 & $(0.270,0.330)$ & $<0.01$ & 0.008 & $(0.006,0.010)$ & 7.111 & $<0.01$ \\
\hline Maternal weight $(\mathrm{kg})$ & 0.015 & $(0.014,0.016)$ & $<0.01$ & -0.002 & $(-0.003,-0.001)$ & -3.952 & $<0.01$ \\
\hline Birth weight (kg) & 2.110 & $(2.080,2.140)$ & $<0.01$ & 2.148 & $(2.111,2.185)$ & 113.389 & $<0.01$ \\
\hline Birth length $(\mathrm{cm})$ & 0.206 & $(0.200,0.212)$ & $<0.01$ & -0.014 & $(-0.021,-0.008)$ & -4.515 & $<0.01$ \\
\hline
\end{tabular}

Notes: aSimple linear regression (outcome as head circumference, $\mathrm{cm}$ ). bMultiple linear regression $\left(R^{2}=0.677\right.$; The model fits reasonably well; model assumptions are met; there was no interaction between independent variables, and no multicollinearity problem). ${ }^{c}$ Crude regression coefficient. ${ }^{d} U$ nadjusted regression coefficient.

Abbreviations: SLR, simple logistic regression; MLR, multiple logistic regression. 
have contributed to the variance of birth parameters for these countries. There is a possibility that comparison with the WHO growth standard have contributed to the high proportion of microcephaly infants in our study. Besides, $>90 \%$ of microcephaly newborns in our study did not have any gross abnormalities recorded at birth to suggest any possibility due to congenital anomaly. However, the results obtained were not interpreted in relation to the gestational age of the newborns, birth weight, birth length, and other clinical case findings. Therefore, there might be a possibility that these newborns have intrauterine health problems which might cause growth and survival problems later. In our hospital delivery system, all newborns were screened by pediatricians before discharge, and those with identified problems in birth parameters were followed up by the pediatricians in our clinic.

Our study on head circumference of newborns at birth did not show any substantial difference compared to the study by Boo et $\mathrm{al}^{8}$ in 1994 . Boo et $\mathrm{al}^{8}$ conducted a longitudinal study with a sample size of 10,000 healthy infants born between 1990 and 1991, which demonstrated significant variation in head circumference among the three main ethnic groups. Malay and Chinese newborns were found to have significantly larger head circumference compared to Indian newborns in the birth cohort. In our study using birth cohorts from 2011 to 2015, different races were associated with different risks of microcephaly. Chinese infants were found to have less risk of microcephaly compared to others. However, both the studies were based on data from a single tertiary center in an urban setting, which may not be representative of all Malaysian infants, which is the limitation of the present study.

Contrary to our study, the study by Boo et $\mathrm{a}^{8}$ excluded infants with abnormalities and infants whose mothers had comorbidities. There are debates on whether the data should be generated from a non-selected population sample or from selected "healthy" subjects with no known factors affecting their growth during the construction of the gestation-specific growth standard. Cole ${ }^{29}$ reasoned that it is not logical to construct a reference standard that is targeted at infants who are excluded, by definition, from the reference sample, when one of the important applications of the growth standard is to enable clinicians to identify subjects with growth problems. Nonetheless, it is doubtful whether a reference that truly represents "healthy" growth could ever be constructed because many factors that affect fetal growth remain unidentified. In this study, the authors did not exclude infants with antenatal factors that affect fetal growth; hence, the birth parameters provide a neutral baseline for comparison without any assumptions being made with regard to the quality change to measurement of the antenatal growth of the infants. ${ }^{26}$ Despite the different sampling methods used, the findings in our study were not substantially different from those by Boo et $\mathrm{al}^{8} 25$ years ago.

Apart from the possible overestimation due to the use of the WHO Growth Standard for comparison, healthy newborns with microcephaly in this study could also be explained by the concept of proportionality of head $\operatorname{size}^{30}$ and late manifestation of abnormality. ${ }^{31}$ Hagen et a ${ }^{31}$ reported that the majority of children with microcephaly presented with neurological symptoms at a mean age of $7-8$ months. The proportionality of head size refers to its measurement in relation to body size (eg, a child who is short with a small head circumference is probably normal). A study that supported this concept was the Seattle school study, which showed that children whose head circumferences were proportionate had significantly higher mean academic achievement scores compared to children whose head sizes were relatively small. The IQ scores however did not differ. ${ }^{32}$

Many research articles have shown that advancing age, maternal parity, and shorter maternal height were associated with smaller infant head circumference. ${ }^{16-18,33} \mathrm{~A}$ crosssectional study from Iran reported that the length and head circumference of the neonates increased significantly with maternal age and parity. ${ }^{17} \mathrm{~A}$ study by Kirchengast and Hartmann on the birth outcome of adolescent mothers showed that the offspring of extremely young mothers of age 12-16 years were significantly smaller in all body dimensions compared to the offspring of older adolescent mothers or adult mothers. ${ }^{15}$ Lira et a ${ }^{18}$ also reported in their cohort study that Brazilian children from taller mothers tended to have a larger head circumference at birth.

However, our study reported an unexpected finding that advanced maternal age was associated with a lower risk of microcephaly. This may be due to the role of UKMMC as a premier fertility center, providing advanced fertility treatment to many mothers aged above 35 years. These mothers were under meticulous pre-pregnancy and antenatal care, leading to good birth outcomes. Apart from this, our findings on maternal height and parity influence on the head circumference of infants were similar to other studies.

The strength of this study is in using an electronic database covering one single institution of health care that practices the same protocol over years. Having 5 years' data allows observation of the trend of microcephaly in the center. Using singleton term babies for analysis helps in controlling the influence of multiple pregnancy and preterm birth on head circumference measurement. The limitation of our study lies in being unable to explore the relationship 
between head circumference and other important risk factors. For example, maternal pre-pregnancy and antenatal weight gain, socioeconomic position, dietary status, lifestyle, and environmental exposures such as smoking, alcohol, and lead exposure ${ }^{14,15,19,34-37}$ are important predictors of birth outcomes. The electronic birth census at our center was not designed to capture information on maternal activities and antenatal progression outside the hospital. The data obtained for the present study were anonymous based on data recorded in the labor room. Hence, there is a limitation of assessing information after babies who have been discharged from the labor room to the postnatal ward.

\section{Conclusion}

This study provides updated reference values for the size of head circumference among Malaysian term newborns at 37-41 completed gestational weeks. The risk factors associated with microcephaly are also reported, which can help health care providers monitor the child who is at risk. These reference values are useful for infant care as head circumference at birth is often related to the future health of the newborns. ${ }^{1,18,38-41}$ However, the cross-sectional anthropometric data in this study do not reflect the intrauterine growth of the fetuses and thus are not suitable for use in the evaluation of fetal growth velocity, growth predictors, and long-term outcome. The addition of the variable of birth head circumference in the birth certificate recorded by the registration department will be valuable data for monitoring its trend nationwide rather than being institution-based. Further study is recommended exploring infant growth pattern, cognitive function, and milestones among babies noted to have head circumferences below the third centile. We propose that a longitudinal method with thorough antenatal records, laboratory testing of biomarkers for smoking, and heavy metal exposure are required to explore the relationship between maternal environmental exposure and infant anthropometry in Malaysia. Further assessment of the trend of increase in the number of babies born with microcephaly in the hot spot area of dengue virus in Malaysia, using available data on birth head circumference, birth length, and gestational age, is needed in view of the emergence of the Zika virus. Studies on the relationship between dengue and chikungunya infections during pregnancy and their effects on pregnancy outcome, need to be explored. This is because the Zika virus comes from the same arbovirus group, with the same vector, Aedes mosquitoes, as these other viruses. Retrospective and follow through studies of confirmed microcephaly cases may help determine their causal factors and the potential complications for public health intervention planning, as the majority of Zika virus infections are asymptomatic.

\section{Acknowledgments}

We thank the support staff from the labor room and NICU who were committed to completing the record keeping.

\section{Disclosure}

The authors report no conflicts of interest in this work.

\section{References}

1. Broekman BF, Chan Y-H, Chong Y-S, et al. The influence of birth size on intelligence in healthy children. Pediatrics. 2009;123:e1011-e1016.

2. Berg B. Microcephaly. Encyclopedia of the Neurological Science. Elsevier. 2014;3.

3. Allanson JE, Cunniff C, Hoyme HE, McGaughran J, Muenke M, Neri G. Elements of morphology: standard terminology for the head and face. Am J Med Genet A. 2009;149:6-28.

4. Gulland A. Zika virus is a global public health emergency, declares WHO. BMJ. 2016;352:i657.

5. Ioos S, Mallet HP, Leparc Goffart I, Gauthier V, Cardoso T, Herida M. Current Zika virus epidemiology and recent epidemics. Méd Mal Infect. 2014;44:302-307.

6. Buathong R, Hermann L, Thaisomboonsuk B, et al. Detection of Zika virus infection in Thailand, 2012-2014. Am J Trop Med Hyg. 2015;93:380-383.

7. Tappe D, Nachtigall S, Kapaun A, Schnitzler P, Günther S, SchmidtChanasit J. Acute Zika virus infection after travel to Malaysian Borneo, September 2014. Emerg Infect Dis. 2015;21:911.

8. Boo N, Lye M, Ong L. Intrauterine growth of liveborn Malaysian infants between gestation of 28 to 42 weeks. Sing Med J. 1994;35:163-166.

9. Grummer-Strawn LM, Reinold C, Krebs NF; Centers for Disease Control and Prevention (CDC). Use of World Health Organization and CDC growth charts for children aged 0-59 months in the United States. MMWR Recomm Rep. 2010;59(RR-9):1-15.

10. MOH 2013. Chid homebased record (Buku Rekod kesihatan Kanakkanak). Available from: http://fh.moh.gov.my/v3/index.php/component/ jdownloads/send/20-sektor-kesihatan-kanak-kanak/242-rekod-kesihatan-lelaki-2013-1?Itemid=0. Accessed September 10, 2017.

11. Dwipoerwantoro PG, Mansyur M, Oswari H, Makrides M, Cleghorn G, Firmansyah A. Growth of Indonesian infants compared with World Health Organization growth standards. J Pediatr Gastroenterol Nutr. 2015;61:248.

12. Hui L, Schooling C, Cowling B, Leung S, Lam T, Leung G. Are universal standards for optimal infant growth appropriate? Evidence from a Hong Kong Chinese birth cohort. Arch Dis Child. 2008;93:561-565.

13. Tanaka H, Ishii H, Yamada T, Akazawa K, Nagata S, Yamashiro Y. Growth of Japanese breastfed infants compared to national references and World Health Organization growth standards. Acta Paediatr. 2013;102:739-743.

14. Hernandez-Avila M, Peterson KE, Gonzalez-Cossio T, et al. Effect of maternal bone lead on length and head circumference of newborns and 1-month-old infants. Arch Environ Health. 2002;57:482-488.

15. Ingvarsson RF, Bjarnason AO, Dagbjartsson A, Hardardottir H, Haraldsson A, Thorkelsson T. The effects of smoking in pregnancy on factors influencing fetal growth. Acta Paediatr. 2007;96:383-386.

16. Kirchengast $S$, Hartmann B. Impact of maternal age and maternal somatic characteristics on newborn size. Am J Human Biol. 2003;15: $220-228$. 
17. Shajari H, Marsoosy V, Aslani M, Mohammady M, Heshmaty P. The effect of maternal age, gestational age and parity on the size of the newborn. Acta Medica Iranica. 2006;44:400-404.

18. Lira PIC, Eickmann SH, Lima MC, Amorim RJ, Emond AM, Ashworth ANN. Early head growth: relation with IQ at 8 years and determinants in term infants of low and appropriate birthweight. Dev Med Child Neurol. 2010;52:40-46.

19. Gundacker C, Fröhlich S, Graf-Rohrmeister K, et al. Perinatal lead and mercury exposure in Austria. Sci Tot Environ. 2010;408:5744-5749.

20. Vital Statistics Malaysia, 2014. Available from: https://www.dosm.gov. my/v1/index.php?r=column/cthemeByCat\&cat=165\&bul_id=eUM5SG RBZndGUHRCZTc2RldqNGMrUT09\&menu_id=L0pheU43NWJwR WVSZklWdzQ4TlhUUT09. Accessed September 10, 2017.

21. Wardlaw TM. Low birthweight: country, regional and global estimates. UNICEF, 2004. Available from: http://www.who.int/iris/ handle/10665/43184. Accessed September 10, 2017.

22. Division of Family Health Development. Perinatal Care Manual, 3rd Edition. Malaysia: Ministry of Health; 2013.

23. WHO Multicentre Growth Reference Study Group. WHO Child Growth Standards: Length/height-for-age, weight-for-age, weight-for-length, weight-for-height and body mass index-for-age: methods and development. Geneva: World Health Organization, 2006. Available from: http:// www.who.int/childgrowth/standards/technical_report/en/. Accessed September 10, 2017

24. De Onis M, Garza C, Victora CG, Onyango AW, Frongillo EA, Martines J. The WHO Multicenter Growth Reference Study: planning, study design, and methodology. Food Nutr Bull. 2004;25:S15-S26.

25. Aris IM, Gandhi M, Cheung YB, et al. A new population-based reference for gestational age-specific size-at-birth of Singapore infants. Ann Acad Med. 2014;43:439-447.

26. Fok T, So H, Wong E, et al. Updated gestational age specific birth weight, crown-heel length, and head circumference of Chinese newborns. Arch Dis Child Fetal Neonatal Ed. 2003;88:F229-F236.

27. National Healthcare Group, Polyclinics. Child Health Services Immunisation and Child Development.; 2015. Available from: https:// www.nhgp.com.sg/Our_Services/General_Medical_Services/Child_ Health_Services/. Accessed September 10, 2017.

28. Elmali F, Altunay C, Mazicioglu MM, Kondolot M, Ozturk A, Kurtoglu S. Head circumference growth reference charts for Turkish children aged 0-84 months. Pediatr Neurol. 2012;46:307-311.

29. Cole T. Some questions about how growth standards are used. Horm Res. 1996;45(Supp1 2):18-23.
30. Johnson DE. Does size matter, or is bigger better? The use of head circumference in preadoption medical evaluations and its predictive value for cognitive outcome in institutionalized children. Minneapolis, International Adoption Clinic, University of Minnesota. 2003. Available from http://citeseerx.ist.psu.edu/viewdoc/download?doi=10.1.1.615.77 $78 \&$ rep=rep $1 \&$ type $=$ pdf.

31. Hagen M, Pivarcsi M, Liebe J, et al. Diagnostic approach to microcephaly in childhood: a two-center study and review of the literature. Dev Med Child Neurol. 2014;56:732-741.

32. Sells CJ. Microcephaly in a normal school population. Pediatrics. 1977;59:262-265.

33. Neggers Y, Goldenberg RL, Cliver SP, Hoffman HJ, Cutter GR. The relationship between maternal and neonatal anthropometric measurements in term newborns. Obstetr Gynecol. 1995;85:192-196.

34. Brantsæter AL, Birgisdottir BE, Meltzer HM, et al. Maternal seafood consumption and infant birth weight, length and head circumference in the Norwegian Mother and Child Cohort Study. Br J Nutr. 2012;107: 436- 444.

35. Kāllén $\mathrm{K}$. The impact of maternal smoking during pregnancy on delivery outcome. Eur J Public Health. 2001;11:329-333.

36. Telatar B, Comert S, Vitrinel A, Erginoz E, Akin Y. The effect of maternal anemia on anthropometric measurements of newborns. Saudi Med J. 2009;30:409-412.

37. Thame M, Wilks RJ, McFarlane-Anderson N, Bennett FI, Forrester TE. Relationship between maternal nutritional status and infant's weight and body proportions at birth. Eur J Clin Nutr. 1997;51:134-138.

38. Bartholomeusz H, Courchesne E, Karns C. Relationship between head circumference and brain volume in healthy normal toddlers, children, and adults. Neuropediatrics. 2002;33:239-241.

39. Eriksen HL, Kesmodel US, Underbjerg M, Kilburn TR, Bertrand J, Mortensen EL. Predictors of intelligence at the age of 5: family, pregnancy and birth characteristics, postnatal influences, and postnatal growth. PLoS One. 2013;8:e79200.

40. Gale CR, O'Callaghan FJ, Bredow M, Martyn CN. The influence of head growth in fetal life, infancy, and childhood on intelligence at the ages of 4 and 8 years. Pediatrics. 2006;118:1486-1492.

41. McKeague IW, Brown AS, Bao Y, Hinkka-Yli-Salomäki S, Huttunen J, Sourander A. Autism with intellectual disability related to dynamics of head circumference growth during early infancy. Biol Psychiatry. 2015;77:833-840.

42. World Health Organization. Child growth standards. Available from: http://www.who.int/childgrowth/en. Accessed September 12, 2017.
Research and Reports in Neonatology

\section{Publish your work in this journal}

Research and Reports in Neonatology is an international, peer-reviewed open access journal publishing original research, reports, editorials, reviews and commentaries on neonatal health. The manuscript management system is completely online and includes a very quick and fair

\section{Dovepress}

peer-review system. Visit http://www.dovepress.com/testimonials.php to read real quotes from published authors. 